\title{
Montana's Early Childhood Educators: Recruiting and Retaining an Essential Workforce
}

\author{
Christine Lux ${ }^{1}\left[{ }^{10} \cdot\right.$ Cassandra Noble $^{2} \cdot$ Nanci Red Bird $^{3}$
}

Accepted: 14 January 2022 / Published online: 11 February 2022

(c) The Author(s), under exclusive licence to Springer Nature B.V. 2022

\begin{abstract}
Shifting realities across the world have emphasized the need to change early childhood systems thinking. Specifically, a quality early childhood workforce was in high demand before the COVID-19 pandemic and will continue to be in demand until sustainable recruitment and retention efforts are achieved. Encouraging more professionals to enter and stay in the field of early childhood education involves building an understanding of the current workforce through analyzing the influence of age, role, education, wages, and access to incentives on career motivation. In this case study, a rich description of Montana's early childhood workforce is presented along with recommendations to strengthen the state's early childhood workforce systems. Results of survey and focus group data collection and analysis confirmed the pervasive compensation disparity that exists in the early childhood workforce and revealed the need for financial incentives to pursue and attain higher education degrees to help ensure the delivery of quality early childhood education. Specific recommendations for policy change include sharing the data across other state systems and with other nations for the purpose of supporting the growth and development of the early childhood workforce in the United States and beyond.
\end{abstract}

Keywords Early childhood $\cdot$ Workforce $\cdot$ Incentives

\section{Introduction}

As a strategy to support young children and families, and thus strengthen communities, early education experiences matter. Shared international perspectives about the benefits of early education include the sentiment that all aspects of children's development can be supported, enhanced, and sustained by early interventions (Nores \& Barnett, 2010; Shonkoff et al., 2012; Fleer \& van Oers, 2018). Building

Christine Lux

christine.lux@montana.edu

Cassandra Noble

cassandra.noble@montana.edu

Nanci Red Bird

nanci.redbird@umwestern.edu

1 Department of Health \& Human Development, Montana State University, 210D Herrick Hall, Bozeman, MT 59717, USA

2 Early Childhood Project, Montana State University, P.O. Box 173540, Bozeman, MT 59717, USA

3 Division of Education, University of Montana - Western, 710 S. Atlantic Street, Dillon, MT 59725, USA on this shared understanding, Kagan and Roth (2017) suggest that shifting social, economic, technological, and environmental realities across the world have highlighted the necessity for systematic change to early childhood systems thinking. Adaptations to family relationships as well as increased family mobility, sometimes resulting in episodic poverty that could become chronic, has placed new demands on early childhood systems, requiring increased services to meet families' social and economic needs. At the heart of these demands is the call to action for universal policy to recruit, retain, and build a strong early childhood workforce that can help ensure every child's access to an education that best supports and impacts their early experiences.

The purpose of this research is to share the results of a case study investigation of early childhood workforce efforts in one northwestern state in the United States. Delving into Montana's early childhood workforce could address policy change intended to advocate for the early childhood profession and therefore support young children and their families. Research efforts could build a comprehensive understanding of the influence of age, role, education, wage, and access to incentives on the motivation to enter into and stay in the early childhood workforce. Findings could provide insight 
into sustained recruitment and retention efforts in Montana and across the United States, thus potentially contributing to international dialog as the field of early childhood education moves forward with revised early care and education guidelines, policies, and procedures in response to COVID-19.

\section{Review of the Literature}

Globally, the COVID-19 health crisis has had a profound impact on "children and their families, preservice and inservice teachers of young children, and early childhood teacher educators" (Early Childhood Education Journal, 2020 , p. 533). Parents' access to early care and education for their children is dependent on sustained program operations, including staffing programs with qualified and trained early educators and program administrators. In other words, early childhood programs cannot exist without early childhood program staff. However, a recent report by the European Commission (European Union, 2021) revealed that existing staff shortages in early care and education were exacerbated by the pandemic, thus further limiting available options for children and families.

Similarly, in the United States, access to early care and education was in high demand before the COVID-19 pandemic with national data suggesting that half of the families in the United States experience difficulty finding available care for children (Sochet, 2019). In the midst of COVID-19, a national survey of 5000 early care and education programs reported more staggering statistics: nearly $50 \%$ of survey respondents had completely closed their programs and of those programs that remained open, $85 \%$ were operating at half capacity or less, thus further limiting the availability of care (NAEYC, 2020a, 2020b). One solution to the crisis in available early care and education is to recruit and retain a highly qualified workforce and encourage more professionals to enter and stay in the field of early childhood education, consistent with the recommendations presented by Organisation for Economic Cooperation and Development and the National Research Council.

\section{Recruiting and Retaining the Early Childhood Workforce}

A central aspect to early childhood systems change is a reexamination of the workforce and an analysis of how to recruit and retain early childhood professionals who will provide support to children and families. In response to the international challenge of recruiting and retaining qualified early care and education professionals, the Organisation for Economic Cooperation and Development (OECD) presented a series of policy recommendations geared toward countries who are struggling to elevate the status of the early childhood profession. Suggested recruitment strategies include providing information about the value and worth of the profession as well as incorporating more pre-service field experience and training into existing university and higher education programs. Across the world, professional development and degree attainment must be affordable and accessible to attract and build the early childhood workforce. Retention efforts such as improving wages and clarifying pathways to career advancement are also included in the OECD report (OECD, 2019).

These, and other important recommendations have influenced early care and education in the United States. Before the OECD recommendations were published, the National Research Council (NRC)'s Transforming the Workforce report encouraged an improved knowledge base and set of competencies for early childhood educators, enhanced higher education programs, and strengthened systems that support every facet of the early childhood workforce, which includes financial support for workforce development (National Research Council, 2015). Finding and securing sustained incentives to attain higher education degrees can ensure the preparation needed to successfully operate an early childhood program and provide high quality care for young children in working families (NAEYC, 2020a, 2020b).

\section{Methods}

A case study methodology was selected for this study to gather in-depth information about Montana's early childhood workforce utilizing data collected by the Montana Early Childhood Project (ECP), the state's Child Care Development Fund (CCDF) outreach program, dedicated to improving the quality of programs and services for Montana's young children and their families. Workforce data collected via the Practitioner Registry maintained by the ECP includes education, certifications, employment, and a record of professional development and achievements. Wage and benefit data are not collected in the current system, leaving a gap of knowledge about the workforce that could reveal indicators of motivation to persist in the early care and education profession. Therefore, survey and focus group interview questions were designed in this case study to fill that gap and provide both quantitative and qualitative data for analysis.

\section{Sample}

The Practitioner Registry is open to all members of Montana's early childhood workforce, and required as of July 2018 for those who are employed by a licensed early care and education facility, including family, group, and centerbased programs. At the start of this research project, the ECP had obtained data on approximately 3500 registry 
participants, representing an estimated $50 \%$ of the early childhood workforce in Montana.

\section{Measures}

The exploratory nature of this study led the research team to develop and administer an online survey and conduct focus groups via telephone to better understand trends in wages, education, incentives, and motivation to stay in the early childhood profession. Qualitative, anecdotal evidence about Montana's early childhood professionals had not been obtained through rigorous research methods prior to this study.

Twenty-four survey questions were developed using other state models as well as input from a variety of stakeholders in Montana with vested interest to recruit, retain, and support a highly qualified, valued, and well-compensated early childhood workforce. Fixed-response demographic questions included age, role, years in the early childhood field, and years at current job. Questions about wages allowed participants to report hourly, monthly, or annual salary data, and also to indicate their last wage increase. Respondents selected the types of benefits offered by their employer (e.g., health insurance, paid time off, etc.), and also were invited to provide additional information about benefits offered and/or received. Regarding education, survey participants recorded their highest degree received and current enrollment status in higher education. Participants were also asked about any forms of financial assistance they received for their education, in particular the Montana Preschool Development Grant (PDG) Leadership and Financial Assistance awards, designed to provide tuition assistance and educational materials support to professionals seeking an early childhood teaching endorsement or early childhood education master's degree. Incentives and motivation to stay in the early childhood field were measured using Likert scale questions such as how likely are you to stay in the field of early care and education? and how important is (pay, benefits, job satisfaction, etc.) in deciding to stay in your current position? One open-ended question at the end of the survey encouraged participants to share any other comments that might contribute toward a better understanding of Montana's early childhood workforce, and also invited participants to indicate their interest in participating in a focus group to provide further insight. Focus group questions were aimed to better understand how each participant came into the early childhood profession, the incentives that were available to support attainment of higher education degrees, and their motivations to stay in the field. See the "Supplementary material" for a complete list of survey and focus group questions.

Upon Montana State University Institutional Review Board (IRB) approval, the survey was delivered electronically in December 2018 to 3471 participants who met any one of three criteria: (1) current or recent member of the Practitioner Registry (active within the prior eighteen months), (2) had a currently submitted application to the Practitioner Registry, or (3) had ever previously applied for or received the Leadership and Financial Assistance award through the Montana Preschool Development Grant (PDG). Survey participation was incentivized with raffle prizes of $\$ 50$ worth of children's books which was awarded to nine survey participants. The research team was particularly interested in receiving feedback and learning more from those who had received financial assistance, and so the 76 individuals in the survey who had received PDG Leadership and Financial Assistance awards were asked to indicate their interest in participating in a focus group. Of these, eight participants engaged in one of two focus groups held in February 2020.

\section{Survey Results}

Eight hundred sixty-nine respondents provided consent to participate in the research study and completed the survey, representing a $25 \%$ rate of return. Questions about age, role, and years of experience in the early childhood profession contributed to a descriptive understanding of the early childhood workforce. Data regarding wages provided evidence of low compensation, and information about benefits helped build an understanding of incentives to stay in the field. An examination of education attainment by age and role further described workforce trends and potential areas of needed support. An analysis of motivation to stay in the field as well as examination of open-ended comments yielded rich insight into recruiting and retaining a highly qualified early childhood workforce in Montana.

\section{Age}

Members of the early childhood workforce in Montana represented all age categories (Fig. 1). However, nearly half of the workforce represented in the sample (48\%) was between 31 and 50 years old $(n=405)$ and just over half of the workforce $(52 \%)$ was over 40 years old $(n=434)$. In other words, the majority of the workforce (77\%) that participated in this study was over 31 years old.

\section{Role}

Survey participants were asked to select among a variety of role categories (director/owner, program administrator, lead teacher, and assistant teacher) to best describe their current position. Role types on the survey were selected based on broad categories represented in Montana childcare licensing. Although the categories seemed distinct, an "other" category 


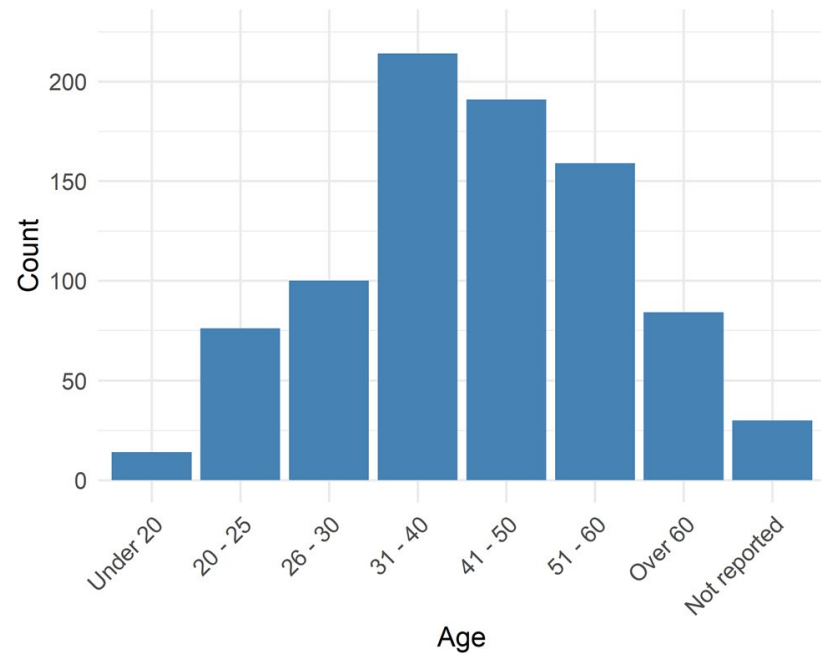

Fig. 1 Montana's early childhood workforce by age range $(n=839)$

was also included and selected by almost $16 \%$ of respondents $(n=131)$. The director/owner category was selected by $34 \%$ of the sample $(n=288)$, followed by $29 \%$ of respondents that indicated lead teacher as their role $(n=246)$ and $14 \%(n=119)$ that indicated assistant teacher. Only $7 \%$ of survey participants $(n=55)$ identified themselves as program administrators. Distribution of role types are displayed in Fig. 2.

\section{Role by Age}

A closer look at survey data revealed a better understanding of the kinds of positions held by Montana's early childhood workforce at different ages. Eight hundred thirty-eight participants reported both age and role type. Among survey

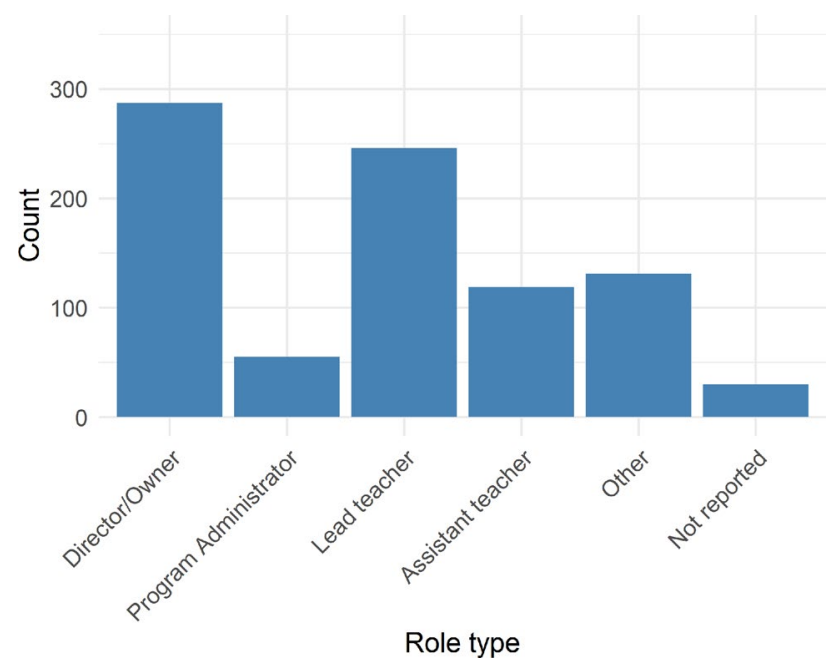

Fig. 2 Montana's early childhood workforce by role type $(n=839)$ participants less than 20 years old, $57 \%$ of respondents reported their role as an assistant teacher $(n=8)$. Among respondents aged $20-25$ years old, 3\% $(n=8)$ reported their role as director or owner, but $76 \%$ of respondents in that age span $(n=58)$ reported holding a lead or assistant teacher position. Among survey participants aged 26-30 years old, $45 \%$ reported holding a lead teacher position $(n=45)$, with just under $20 \%$ of professionals in that age group reporting director/owner or assistant teacher positions $(n=18)$. Among respondents between 31 and 40 years old, $41 \%$ reported holding a director/owner position $(n=88)$, followed by $28 \%$ in lead teacher roles $(n=60)$. Among survey participants between the ages 41 and 50 years old, $44 \%$ indicated a director/owner role $(n=88)$, and another $25 \%$ reported lead teacher roles $(n=48)$. Distribution of role types by age ranges is displayed in Fig. 3.

Data collected also suggested that the early childhood profession often requires "wearing many hats" and taking on more than one role, particularly among family and group program professionals. For example, one respondent indicated "Family provider-I do it all." Of the 131 "other" responses, $20 \%$ indicated that they held more than one role.

\section{Years of Experience in the Early Childhood Profession}

Survey questions regarding years of experience included one question about longevity in the field and one question about employment length in their current position. Eight hundred thirty-nine survey participants reported their years of experience. Of those, $45 \%(n=374)$ reported employment in the early childhood profession for less than 10 years, while $27 \%$

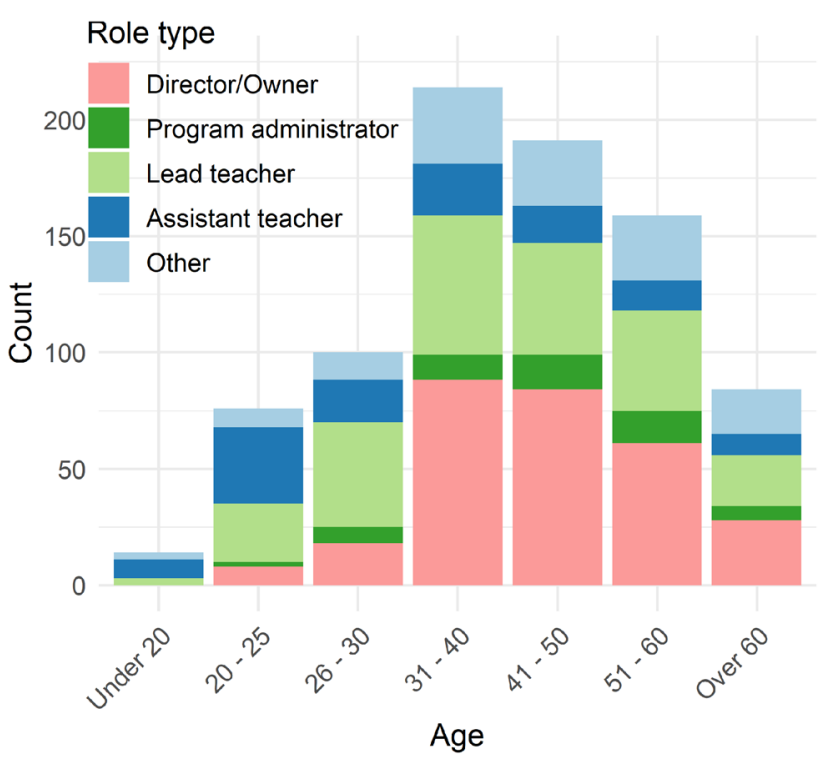

Fig. 3 Role types by age range $(n=838)$ 
$(n=229)$ reported between 11 and 20 years of experience, and $28 \%(n=236)$ reported more than 20 years of experience. Seventeen percent of respondents $(n=145)$ reported more than 25 years of employment in the early childhood profession. Distribution of data regarding longevity in the field of early childhood is displayed in Fig. 4.

Data regarding years of employment suggests that the majority of survey respondents are new to their current position. Thirty-five percent of the sample $(n=293)$ has held their current position for less than three years. Another $22 \%$ of respondents $(n=185)$ reported 3-5 years of employment in their current positions while $16 \%$ of the sample $(n=134)$ reported 6-10 years of employment in their current positions. Only $9 \%$ of respondents $(n=74)$ reported $11-15$ years of employment in their current positions and just $6 \%$ of respondents $(n=51)$ of respondents reported 16-20 years of employment in their current positions. The greatest amount of longevity in their current position-more than 20 yearswas reported by $12 \%$ of the sample $(n=102)$. Data are displayed in Fig. 5.

\section{Wages}

Survey participants were able to report hourly, monthly, or annual wages and salaries. Monthly salaries were converted to and are included with annual salaries. Program administrators reported the highest earnings, while assistant teachers earned the least. Wage results by role type are displayed in Table 1.

\section{Benefits}

Approximately $60 \%(n=472)$ of respondents reported that some benefits were offered by their employer. Of the list of possible benefits, paid time off was the most common with $25 \%$ of all respondents reporting this benefit $(n=426)$. Financial support for professional development and education, health insurance, and retirement options were also very popular (15-20\%). Free or reduced childcare and paid

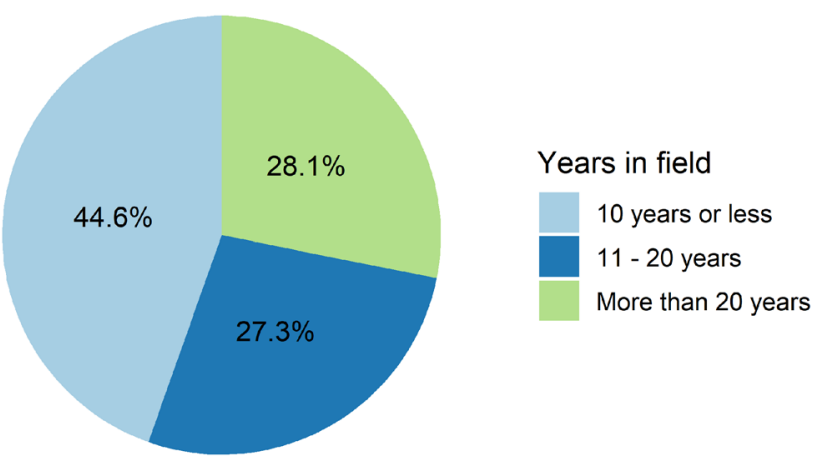

Fig. 4 Years employed in the early care and education field $(n=839)$

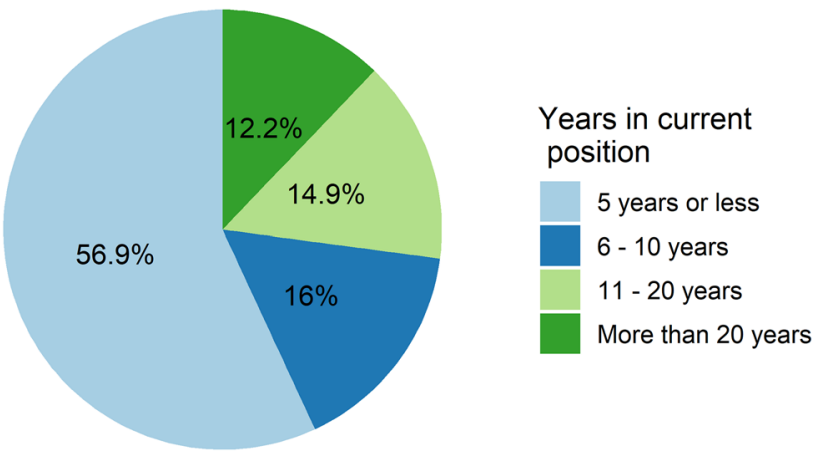

Fig. 5 Years employed in current position $(n=839)$

membership in a professional organization were less common with about $7-8 \%$ of survey respondents reporting these benefits.

\section{Education}

Survey questions regarding degree and education attainment included selecting the highest level of education attained, and indication of current enrollment status in higher education and anticipated date of graduation. Figure 6 shows the distribution of the 791 participants who reported their highest degree received. One third of the workforce reported a bachelor's degree as their highest degree earned $(n=267)$, followed by $29 \%$ with a high school diploma or equivalent $(n=229), 18 \%$ with an associate degree $(n=139)$, and $10 \%$ with a master's degree $(n=83)$. Eight percent of participants $(n=67)$ reported a Child Development Associate credential as their highest level of education. Less than one percent of survey participants have received a doctorate degree $(n=3)$ or did not complete high school $(n=3)$. Fifteen percent of respondents $(n=122)$ indicated they were currently enrolled in college.

\section{Motivation to Stay in the EC Field}

Participants were asked about their likelihood to stay in their current position and also their likelihood to stay in

Table 1 Average hourly and annual wages by role $(n=852)$

\begin{tabular}{lllll}
\hline Role type & $\begin{array}{l}\text { Average } \\
\text { hourly } \\
\text { wage }\end{array}$ & $\begin{array}{l}\text { Average } \\
\text { annual } \\
\text { salary }\end{array}$ & $\mathrm{n}$ & $\begin{array}{l}\text { Percent of } \\
\text { role types }\end{array}$ \\
\hline Assistant teacher & $\$ 11.03$ & $\$ 22,140$ & 124 & $15 \%$ \\
Lead teacher & $\$ 12.99$ & $\$ 35,883$ & 249 & $29 \%$ \\
Other & $\$ 15.23$ & $\$ 35,206$ & 135 & $16 \%$ \\
Director/Owner & $\$ 16.22$ & $\$ 34,457$ & 289 & $34 \%$ \\
Program administrator & $\$ 18.76$ & $\$ 37,180$ & 55 & $6 \%$ \\
\hline
\end{tabular}




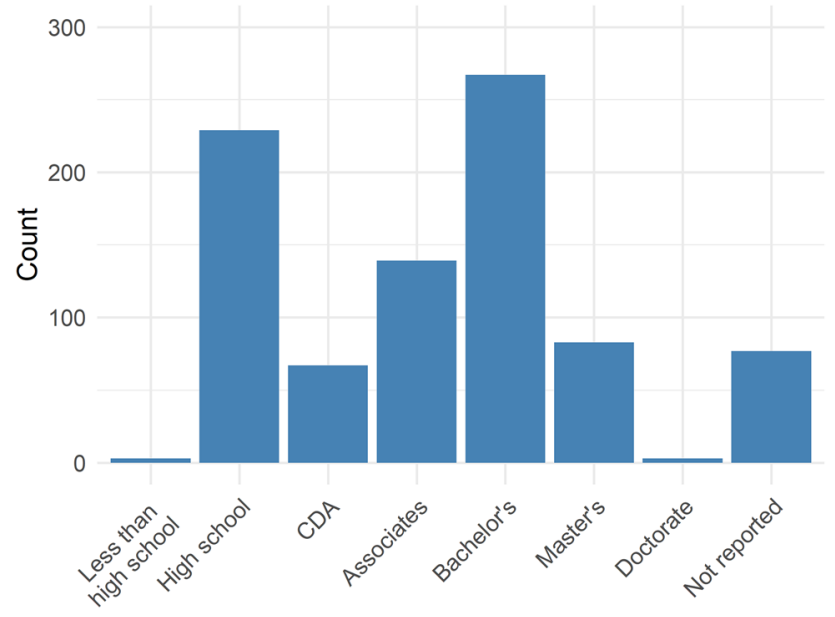

Highest level of education

Fig. 6 Highest degree earned by Montana's early childhood workforce $(n=791)$

the early childhood profession over the next three years. Of the 798 who reported their intentions of remaining in the field, $82 \%(n=651)$ reported that they were extremely or somewhat likely. Three-quarters of the 797 respondents who reported their intentions of remaining in their current position $(n=596)$ reported extremely or somewhat likely.

\section{Open Ended Feedback}

Participants provided extensive comments about their experience in Montana's early childhood workforce in the open-ended question at the end of the survey. Responses were analyzed and coded by theme by each member of the research team to ensure reliability of data, and several common themes emerged, including education, scholarships, pay, joy, the Practitioner Registry, and benefits. Figure 7 shows these themes.

\section{Focus Group Results}

Eight survey participants who had received financial assistance through the Montana Preschool Development Grant provided insight about their experience in Montana's early childhood workforce by engaging in one of two focus groups held in February 2020. Because education was the most prominent theme of the open-ended feedback gathered in the survey, specific questions about attainment of higher education degrees were included in the focus groups. Additionally, participant insight about entry into the field, impact of incentives, and ongoing professional goals provided a deeper understanding of this specific sector of the workforce and gave insight into motivation to stay in the field. Although

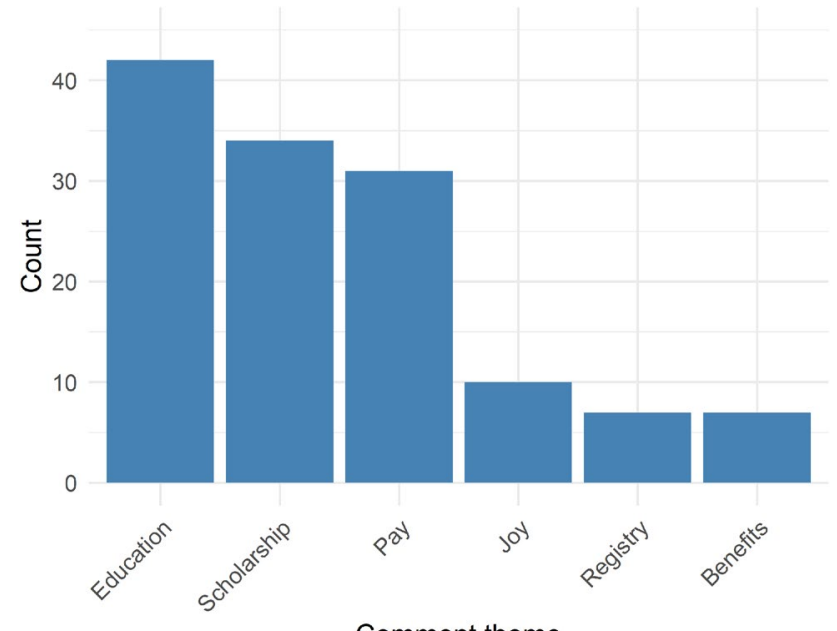

Comment theme

Fig. 7 Open-ended comment themes $(n=158)$

focus group participant identities are kept anonymous in this report, demographic data was obtained by matching identities to Practitioner Registry data.

The eight focus group participants came from eight different counties in Montana, with half residing in larger cities, and half from smaller towns. There was also representation from five of Montana's seven Child Care Resource and Referral (CCR\&R) regions. All participants were Caucasian and non-Hispanic. An attempt was made to include a more racially and ethnically diverse group, however many eligible and willing participants were unable to participate. Ages of the focus group participants ranged from 29 to 53, with an average age of 39 . The average number of years participants had been working in the field was 12, with a range from 6 to 25 years.

\section{Entry into the Field of Early Childhood Education}

Each participant told a unique story about their path to the profession, representing a wide variety of experience. Of the eight focus group participants, six talked about becoming a parent as a catalyst for entering the early childhood workforce. The struggle to find quality care led four participants to start their own early care and education programs.

\section{Impact of Incentives to Attain Higher Education Degrees}

Participants cited the importance of higher education and the opportunity for financial support as motivation to obtain a teaching credential or master's degree. Prior to receiving a financial assistance award, two participants had not completed a higher education degree, one had an associate degree in early childhood, and five had bachelor's degrees. 
Among the bachelor's degrees, two were in related fields (e.g., Elementary Education), and three were in unrelated fields (e.g., Art).

Previous bachelor's degrees in both related or unrelated fields, such as elementary education or art, did not prevent three participants from pursuing and completing a second bachelor's or even graduate level degrees in early childhood, however one participant explained, "I wouldn't have attempted it [without the assistance]." Another comment was "financial assistance helped formalize my commitment to the field." Another participant expressed gratitude for the financial support, but also explained that she "can be there for parents, for children. That's why I go to school." This same participant is thinking of pursuing a specialized degree to provide targeted support for struggling learners.

Montana provides other incentives to registry participants, beyond tuition and fees to cover higher education costs. Five of the participants had previously received partial tuition funding through an established higher education incentive award, which provides a set amount of assistance per semester based on the number of early childhood credits earned. Two participants also completed the Montana Early Childhood Apprenticeship Program (MECAP), an incentive program that provides on-the-job training with the support of a mentor as well as college-level classroom instruction. One participant started her educational career with an associate degree as the end goal, but went on to complete her bachelor's degree and then became an apprenticeship sponsor. Focus group participants shared their interest in more financial support towards achieving a higher education such as a service payback or additional scholarship opportunities to help them complete their degrees.

\section{Ongoing Professional Goals}

There was clear voice about the passion for early childhood education and the commitment to young children and their families throughout the focus groups. One participant spoke about her role in a small Montana community, explaining about children that she got to "start them off" and "see them grow up." This joy has kept her in the field. Another participant also spoke about her commitment to the community, explaining that she holds high standards in her program because she wants to provide for the community. Her next professional goal is to "advocate for quality care and turn this into a profession." Similarly, another participant sees herself leaving teaching for a leadership position to advocate for publicly funded pre-K, explaining that "this is a really important time .... to solve community problems." The theme of leadership and advocacy was summed up by one participant who wants to "venture into bigger things" by taking a more active role in state boards and becoming a conference presenter.

\section{Discussion and Recommendations}

In this study, new insight was gained about Montana's early childhood workforce, including information about role, age, education, wages, motivation to stay in the early childhood field, and impact of financial incentives. Several interesting conclusions and suggestions for further research are highlighted in the sections below.

\section{Role}

As previously reported, almost $16 \%$ of survey respondents $(n=131)$ selected "other" as their role type. Within the $31-40$ years old age range, $15 \%$ of respondents $(n=33)$ indicated different role types and professional responsibilities, ranging from caregiver to mental health consultant to elementary school teacher. This suggests that many early childhood professionals contribute to the workforce and provide services to children and families in unique ways, beyond the categorizations provided in the survey. Among focus group participants, a variety of typical programs and roles were represented, such as center director, group childcare owner, and head start teacher, but also ranged from undergraduate student completing her student teaching to a community college faculty member, indicating that access to higher education and degree attainment provides different opportunities for career advancement throughout different stages of professional growth.

A variety of "other" role types reported on the survey suggests inconsistencies among agencies and organizations across the state that employ early childhood professionals. For example, the Montana Early Childhood Project Practitioner Registry uses the role types "early childhood teacher," "assistant teacher," and "director/owner." Similarly, Montana Child Care Licensing uses the role types early childhood lead teacher, assistant teacher, and director, reflecting recent changes to licensing rule. However, some data tracking systems in Montana continue to use the word "caregiver" to refer to early childhood professionals employed by early care and education programs. It is recommended that all early childhood systems use consistent language and titles, such as early childhood educator, that are aligned to the language and standards used by the National Association for the Education of Young Children (NAEYC) that advocate for and professionalize the field of early childhood education.

\section{Role by Age}

Among survey participants under age 20, 21\% $(n=3)$ reported that they are student aides helping lead teachers. This suggests that a portion of the workforce might be enrolled in higher education and is employed by an early 
care and education program, perhaps on a college campus. As the workforce gets older, age somewhat predicts moving into roles with greater management responsibility, such as taking on a director or administrative role. This also has implication for wage and salary, as management positions earn more money than teaching roles. Focus group data further supports this claim, as participants with the most years of experience held higher level positions.

\section{Education}

An analysis of education attainment among survey participants at various ages and within different role types revealed trends and characteristics about Montana's early childhood workforce. Survey data, shown in Figs. 8 and 9, suggests that high school and bachelor's degree attainment were fairly evenly split in each age range. Master's degrees became less prevalent as age increased, and bachelor's degrees were most commonly associated with director/owners and lead teachers.

Interestingly, focus group participants provided some negative sentiment about the impact of their education and cited some of the challenges to completing a degree. One respondent explained that "the coursework wasn't groundbreaking" and another shared that she hasn't "received a lot of benefit from my education." Follow up questions were not asked to better understand the kinds of benefits that were anticipated, but one participant explained that "professionally, I am still in the same position," suggesting that perhaps she expected to achieve a higher-ranking position in her place of employment. One participant spoke about the "hoops to jump through" to obtain her teaching credential, explaining that, in particular, student teaching was very difficult to complete while also trying to earn an income. She suggested, and the researchers agreed, that financial incentives are crucial

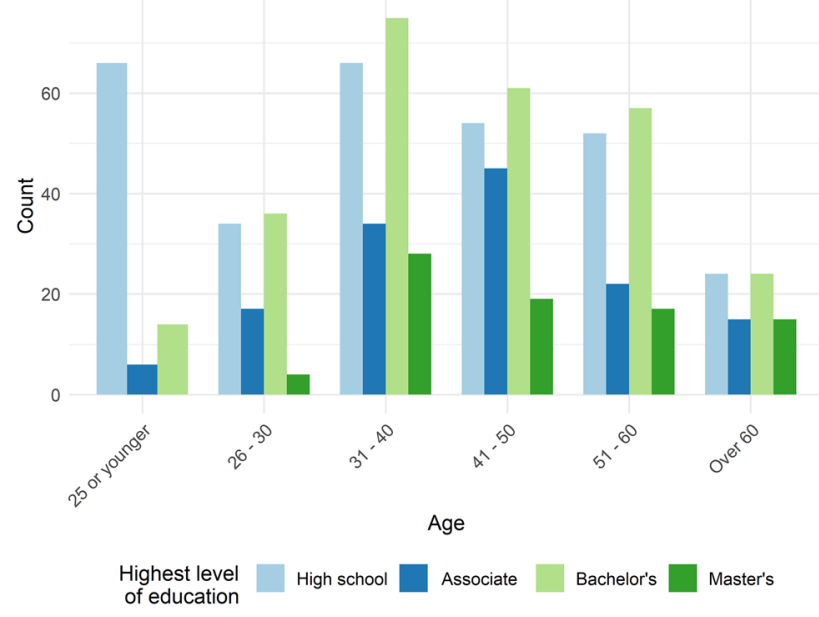

Fig. 8 Education levels by age $(n=785)$

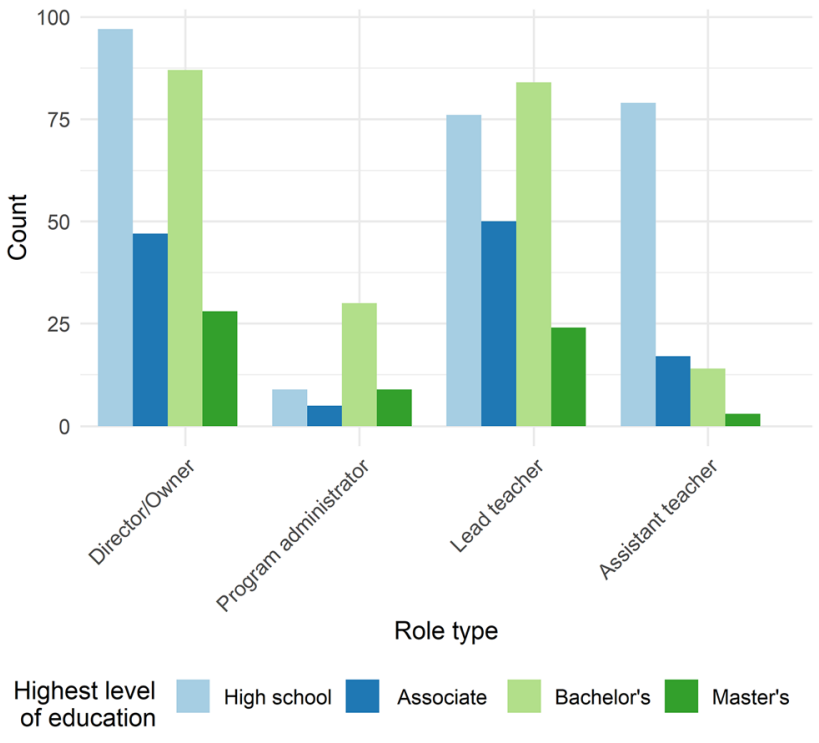

Fig. 9 Education levels by role type $(n=659)$

to a teacher candidates' ability to ensure financial stability while finishing a teaching endorsement.

\section{Wages}

The Center for the Study of Child Care Employment reported that "teaching in early care and education (ECE) programs is one of the lowest-paid occupations in the United States" (Whitebook, et al., 2018, p. 1). In other fields, salary and wages can be indicative of the value of work completed, but chronic low wages persist despite the value placed on early childhood education. One focus group participant revealed that "families view me as more professional but I' $m$ not paid more." Open ended comments on the survey also revealed strong themes about pay, following comments about education and scholarship. One participant noted, "I love the field of Early Childhood and want to stay in this field, but I am having a hard time finding a job that can pay me a living wage and includes benefits."

In this study, wages were reported either hourly, monthly, or annually. Curiously, nearly $14 \%$ of survey respondents $(n=120)$ did not provide wage or salary information on the survey. Some program owners explained in the open-ended comments that they do not earn reportable wages, which suggests a need for more professional development about business practices, including tax credits, income reporting, and recognizing financial gain for household expenses that are covered by revenue generated by tuition.

A limitation to the study results was discovered regarding calculation of average earnings. The researchers did not parse out full time or part time employment when participants reported their salary instead of hourly wages, therefore, 
calculations about average earnings may not be accurate. A recommendation for further research is to determine number of hours worked to get a clearer picture of wages. This limitation is consistent with a recent Montana Department of Labor and Industry (DLI) report (Watson, 2019) about earnings for the early care and education workforce. In the DLI report, wage reporting was focused to childcare licensing role types, which are one subset of roles reported in the current study. In the current study and the DLI report, compensation seems to be tied to professional role (i.e. managers are paid more than assistant teachers), but a clearer alignment of pay to education might help establish pay scales and guidance for employers seeking to improve compensation.

\section{Motivation to Stay in the Field}

Survey participants were asked about their likelihood to stay in the early childhood profession and the importance of wage, benefits, personal fulfillment, and opportunities for growth in their career planning. A closer analysis of these motivators is needed to further understand perceptions of Montana's early childhood workforce. Continued analysis and reporting of the qualitative data obtained through the open-ended question on the survey could continue to add to the understanding of Montana's early childhood workforce. Among focus group participants, there was clear sentiment regarding passion for young children and families. The motivation to stay in the field seemed most focused on making a difference in the community.

\section{Conclusion}

Globally, early childhood education is a valuable profession, but it is fraught with compensation disparity and barriers to the pursuit and attainment of higher education degrees. Wages must reflect the education, knowledge, and commitment of professionals who support young children and their families. Degree attainment, coupled with ongoing professional development and mentoring, can ensure the delivery of high-quality early care and education.

Investment in the early childhood workforce, in Montana and beyond, requires a keen understanding of how individuals come into the profession and why they stay. In this study, an understanding was gained regarding Montana's early childhood workforce. Recommendations to further support recruitment and retention efforts resulted from survey and focus group data analysis that revealed some gaps in data collection. Addressing these gaps could help other states, territories, and countries continue to support the early childhood workforce. Specific recommendations for policy change include: (1) utilizing economic data and wage reporting to best align role types with earnings, (2) identifying the diverse role types within the early childhood profession, (3) establishing financial incentives for role advancement, (4) outlining a career path with education attainment achievement recognition, and (5) providing start-up grants and mentorship opportunities to encourage entry into the profession. Recognizing and celebrating early childhood professionals as an essential influence on the health and strength of our communities could spark more effective recruitment and retention, thus supporting young children and their families.

Supplementary Information The online version contains supplementary material available at https://doi.org/10.1007/s10643-022-01308-3.

Acknowledgements The authors wish to thank the dedicated and hardworking members of Montana's early childhood workforce, whose voice and vision continue to make an impact in the lives of young children and their families.

Author Contributions The corresponding author conceptualized the study, wrote the survey and focus group questions, completed a review of the literature, and wrote the first draft of the manuscript. The second author participated with the corresponding author on data analysis. The second author formatted the figures and tables. The second and third authors commented on the manuscript draft.

\section{Declarations}

Conflict of interest The authors have no funding or conflicts of interest to disclose.

Ethical Approval The research study was approved by the Institutional Review Board at Montana State University.

Informed Consent Participants provided informed consent to participate in the survey and focus groups.

\section{References}

Early Childhood Education Journal (Eds.). (2020). Impact of the Covid-19 pandemic on early childhood care and education. Early Childhood Education Journal, 48, 533-536. https://doi.org/10. 1007/s10643-020-01082-0

European Union. (2021). Early childhood education and care and the COVID-19 crisis: Understanding and managing the impact of the crisis on the sector. European Union. https://doi.org/10.2766/ 60724

Fleer, M., \& van Oers, B. (Eds.). (2018). International handbook of early childhood education. Springer Netherlands. https://doi.org/ 10.1007/978-94-024-0927-7

Kagan, S. L., \& Roth, J. L. (2017). Transforming early childhood systems for future generations: Obligations and opportunities. Paper presentation by Sharon Lynn Kagan at the OMEP conference, Transforming Early Childhood Systems for Future Generations, held at Ewha Womans University in Seoul, Korea, from 6 to 8 July, 2016.

NAEYC. (2020, March). Unifying framework for the early childhood education profession. National Association for the Education of Young Children. http://powertotheprofession.org/wp-content/ uploads/2020/03/Power-to-Profession-Framework-03312020web.pdf 
NAEYC. (2020, May 20). A state-by-state look at the ongoing effects of the pandemic on child care. National Association for the Education of Young Children. https://www.naeyc.org/sites/default/ files/globally-shared/downloads/PDFs/resources/topics/ongoing effect_of_pandemic.naeyc_state_by_state.pdf

National Research Council. (2015). Transforming the workforce for children birth through age 8: A unifying foundation. The National Academies Press. https://doi.org/10.17226/19401

Nores, M., \& Barnett, W. S. (2010). Benefits of early childhood interventions across the world: (Under) investing in the very young. Economics of Education Review, 29, 271-282.

Organisation for Economic Co-operation and Development. (2019). Good practice for good jobs in early childhood education and care. https://doi-org.proxybz.lib.montana.edu/10.1787/64562 be6-en

Shonkoff, J. P., Garner, A. S., Siegel, B. S., Dobbins, M. I., Earls, M. F., McGuinn, L., et al. (2012). The lifelong effects of early childhood adversity and toxic stress. Pediatrics, 129(1), e232-e246. https:// doi.org/10.1542/peds.2011-2663

Sochet, L. (2019, March). The child care crisis is keeping women out of the workforce. Center for American Progress. https://cdn.ameri
canprogress.org/content/uploads/2019/03/19103744/ECPP-Child Care-Crisis-report-2.pdf

Watson, A. (2019, April). Understanding the early childhood workforce: A critical component to addressing the state's workforce shortage. Retrieved from: https://www.enhancemt.org/documents/ Watson,\%20Amy\%20-\%202019-04-10\%20-\%20Child\%20Care\% 20Montana\%20Economy.pdf

Whitebook, M., McLean, C., Austin, L. J. E., \& Edwards, B. (2018). Early Childhood Workforce Index-2018. Center for the Study of Child Care Employment, University of California, Berkeley. http://cscce.berkeley.edu/topic/early-childhood-workforce-index/ 2018/

Publisher's Note Springer Nature remains neutral with regard to jurisdictional claims in published maps and institutional affiliations. 